IJMMS 31:10 (2002) 611-617

PII. S0161171202112257

http://ijmms.hindawi.com

(c) Hindawi Publishing Corp.

\title{
CONVERGENCE THEOREMS AND STABILITY \\ RESULTS FOR LIPSCHITZ STRONGLY PSEUDOCONTRACTIVE OPERATORS
}

\author{
ZEQING LIU, LILI ZHANG, and SHIN MIN KANG
}

Received 17 December 2001

\begin{abstract}
Suppose that $X$ is an arbitrary real Banach space and $T: X \rightarrow X$ is a Lipschitz strongly pseudocontractive operator. It is proved that under certain conditions the Ishikawa iterative method with errors converges strongly to the fixed point of $T$ and this iteration procedure is stable with respect to $T$.
\end{abstract}

2000 Mathematics Subject Classification: 47H05, 47H06, 47H14, 47H10.

1. Introduction and preliminaries. Let $X$ be a real Banach space and $J$ denote the normalized duality mapping from $X$ into $2^{X^{*}}$ given by

$$
J x=\left\{f \in X^{*}:\langle x, f\rangle=\|x\|^{2}=\|f\|^{2}\right\},
$$

where $X^{*}$ denotes the dual space of $X$ and $\langle\cdot, \cdot\rangle$ denotes the generalized duality pairing. In the following, $I$ denotes the identity operator on $X$. An operator $T$ with domain $D(T)$ and range $R(T)$ in $X$ is called strongly pseudocontractive if there exists a constant $t>1$ such that for given $x, y \in D(T)$, there exists $j(x-y) \in J(x-y)$ satisfying

$$
\langle T x-T y, j(x-y)\rangle \leq \frac{1}{t}\|x-y\|^{2} .
$$

If $t=1$ in (1.2), then $T$ is called pseudocontractive. Interest in pseudoncontractive mappings stems mainly from their firm connection with the important class of accretive operators, where an operator $T$ is called accretive if for each $x, y \in D(T)$, there exists $j(x-y) \in J(x-y)$ such that

$$
\langle T x-T y, j(x-y)\rangle \geq 0 .
$$

Furthermore, $T$ is called strongly accretive if there exists a constant $k \in(0,1)$ such that for given $x, y \in D(T)$, there exists $j(x-y) \in J(x-y)$ satisfying

$$
\langle T x-T y, j(x-y)\rangle \geq k\|x-y\|^{2} .
$$

It follows easily from (1.2), (1.3), and (1.4) that $T$ is strongly pseudocontractive (resp., pseudocontractive) if and only if $(I-T)$ is strongly accretive (resp., accretive), so that 
the mapping theory for strongly accretive operators (resp., accretive operators) is intimately connected with the fixed point theory of strongly pseudocontractive operators (resp., pseudocontractive operators). It is well known [4] that if $T: X \rightarrow X$ is a Lipschitz strongly pseudocontractive operator, then $T$ has a unique fixed point.

Next we recall the definition of stability. Let $X$ be a Banach space and $T$ be a mapping from $X$ into $X$. Let $x_{0} \in X$ and $x_{n+1}=f\left(T, x_{n}\right)$ define an iteration procedure which yields a sequence of points $\left\{x_{n}\right\}_{n=0}^{\infty}$ in $X$. Suppose that $F(T)=\{x \in X: T x=x\} \neq \varnothing$ and that $\left\{x_{n}\right\}_{n=0}^{\infty}$ converges to a fixed point $p$ of $T$. Let $\left\{y_{n}\right\}_{n=0}^{\infty}$ be an arbitrary sequence in $X$ and $\epsilon_{n}=\left\|y_{n+1}-f\left(T, y_{n}\right)\right\|$. If $\lim _{n \rightarrow \infty} \epsilon_{n}=0$ implies $\lim _{n \rightarrow \infty} y_{n}=p$, then the iteration procedure defined by $x_{n+1}=f\left(T, x_{n}\right)$ is said to be $T$-stable or stable with respect to $T$. Stability results for several iteration procedures for certain contractive definitions have been established in recent papers by several authors, (see $[6,10,11,12]$ and the references therein). In [6], Harder and Hicks showed how such a sequence $\left\{y_{n}\right\}_{n=0}^{\infty}$ could arise in practice and demonstrated the importance of investigating the stability of various iteration procedures for various classes of nonlinear mappings.

It is our purpose in this paper to show that if $X$ is an arbitrary real Banach space and $T: X \rightarrow X$ is a Lipschitz strongly pseudocontractive operator, then under certain conditions the Ishikawa iterative method with errors converges strongly to the unique fixed point of $T$. We also prove that this iteration procedure is stable with respect to $T$. Our results generalize most of the results that have appeared recently. In particular, the results of $[1,2,3,5,6,8,10,11,12,13]$ and a host of others will be special cases of our theorems.

The following lemma plays a crucial role in the proofs of our main results.

LEMMA 1.1 [9]. Let $\left\{a_{n}\right\}_{n=0}^{\infty},\left\{b_{n}\right\}_{n=0}^{\infty}$, and $\left\{c_{n}\right\}_{n=0}^{\infty}$ be three nonnegative real sequences satisfying the inequality

$$
a_{n+1} \leq\left(1-w_{n}\right) a_{n}+b_{n} w_{n}+c_{n}
$$

for all $n \geq 0$, where $\left\{w_{n}\right\}_{n=0}^{\infty} \subset[0,1], \sum_{n=0}^{\infty} w_{n}=\infty, \lim _{n \rightarrow \infty} b_{n}=0$, and $\sum_{n=0}^{\infty} c_{n}<\infty$. Then $\lim _{n \rightarrow \infty} a_{n}=0$.

2. Main results. In the sequel, $k=(t-1) / t$ and $t$ is the constant appearing in (1.2) and $L$ denotes the Lipschitz constant of $T$ with $L \geq 1$.

THEOREM 2.1. Let $X$ be an arbitrary real Banach space and let $T: X \rightarrow X$ be a Lipschitz strongly pseudocontractive mapping. Define the sequence $\left\{x_{n}\right\}_{n=0}^{\infty}$ iteratively by $x_{0}, u_{0}, v_{0} \in X$,

$$
\begin{aligned}
y_{n} & =\left(1-\beta_{n}\right) x_{n}+\beta_{n} T x_{n}+v_{n}, \quad n \geq 0, \\
x_{n+1} & =\left(1-\alpha_{n}\right) x_{n}+\alpha_{n} T y_{n}+u_{n}, \quad n \geq 0,
\end{aligned}
$$

where $\left\{\alpha_{n}\right\}_{n=0}^{\infty},\left\{\beta_{n}\right\}_{n=0}^{\infty}$ are two real sequences and $\left\{u_{n}\right\}_{n=0}^{\infty},\left\{v_{n}\right\}_{n=0}^{\infty}$ are two sequences in $X$ satisfying the following conditions: 


$$
\begin{gathered}
\sum_{n=0}^{\infty} \alpha_{n}=+\infty, \quad 0 \leq \alpha_{n} \leq 1, n \geq 0 ; \\
\frac{k-L(L+1) \beta_{n}-L^{2}(L+1) \alpha_{n}}{1-(1-k) \alpha_{n}} \geq r, \quad 0 \leq \beta_{n} \leq 1, n \geq 0 ; \\
\lim _{n \rightarrow \infty}\left\|v_{n}\right\|=0, \quad \sum_{n=0}^{\infty}\left\|u_{n}\right\|<+\infty ;
\end{gathered}
$$

where $r \in(0,1]$ is a constant. Then $\left\{x_{n}\right\}_{n=0}^{\infty}$ converges strongly to the unique fixed point of $T$.

Proof. It follows from [4, Corollary 1$]$ that $T$ has a unique fixed point $p$ in $X$. Since $T$ is strongly pseudocontractive, it follows from (1.2) that for all $x, y \in X$, there exists $j(x-y) \in J(x-y)$ such that

$$
\langle(I-T) x-(I-T) y, j(x-y)\rangle \geq k\|x-y\|^{2} .
$$

Thus

$$
\langle(I-T-k I) x-(I-T-k I) y, j(x-y)\rangle \geq 0,
$$

and by [7, Lemma 1.1], we have

$$
\|x-y\| \leq\|x-y+s[(I-T-k I) x-(I-T-k I) y]\|
$$

for all $x, y \in X$ and $s>0$. Using (2.1), we obtain that

$$
\begin{aligned}
\left(1-\alpha_{n}\right) x_{n}= & x_{n+1}-\alpha_{n} T y_{n}-u_{n} \\
= & {\left[1-(1-k) \alpha_{n}\right] x_{n+1}+\alpha_{n}(I-T-k I) x_{n+1} } \\
& +\alpha_{n} T x_{n+1}-\alpha_{n} T y_{n}-u_{n} .
\end{aligned}
$$

Note that,

$$
\left(1-\alpha_{n}\right) p=\left[1-(1-k) \alpha_{n}\right] p+\alpha_{n}(I-T-k I) p .
$$

It follows from (2.7), (2.8), and (2.9) that

$$
\begin{aligned}
& \left(1-\alpha_{n}\right)\left\|x_{n}-p\right\| \\
& \geq\left[1-(1-k) \alpha_{n}\right]\left\|x_{n+1}-p+\frac{\alpha_{n}}{1-(1-k) \alpha_{n}}\left[(I-T-k I) x_{n+1}-(I-T-k I) p\right]\right\| \\
& \quad-\alpha_{n}\left\|T x_{n+1}-T y_{n}\right\|-\left\|u_{n}\right\| \\
& \geq\left[1-(1-k) \alpha_{n}\right]\left\|x_{n+1}-p\right\|-\alpha_{n}\left\|T x_{n+1}-T y_{n}\right\|-\left\|u_{n}\right\|,
\end{aligned}
$$

which implies that

$$
\begin{aligned}
\left\|x_{n+1}-p\right\| \leq & \frac{1-\alpha_{n}}{1-(1-k) \alpha_{n}}\left\|x_{n}-p\right\|+\frac{\alpha_{n}}{1-(1-k) \alpha_{n}}\left\|T x_{n+1}-T y_{n}\right\| \\
& +\frac{1}{1-(1-k) \alpha_{n}}\left\|u_{n}\right\| .
\end{aligned}
$$


We have the following estimates:

$$
\begin{aligned}
\left\|x_{n}-y_{n}\right\| & \leq \beta_{n}\left\|x_{n}-T x_{n}\right\|+\left\|v_{n}\right\| \leq(L+1) \beta_{n}\left\|x_{n}-p\right\|+\left\|v_{n}\right\|, \\
\left\|T y_{n}-y_{n}\right\| & \leq(L+1)\left\|y_{n}-p\right\| \leq(L+1)\left(1-\beta_{n}+L \beta_{n}\right)\left\|x_{n}-p\right\|+(L+1)\left\|v_{n}\right\| \\
& \leq L(L+1)\left\|x_{n}-p\right\|+(L+1)\left\|v_{n}\right\| .
\end{aligned}
$$

From (2.1) and (2.12), we have

$$
\begin{aligned}
\left\|T x_{n+1}-T y_{n}\right\| & \leq L\left\|x_{n+1}-y_{n}\right\| \\
& \leq L\left(1-\alpha_{n}\right)\left\|x_{n}-y_{n}\right\|+\alpha_{n} L\left\|T y_{n}-y_{n}\right\|+L\left\|u_{n}\right\| \\
& \leq\left[L(L+1) \beta_{n}+L^{2}(L+1) \alpha_{n}\right]\left\|x_{n}-p\right\|+L(L+1)\left\|v_{n}\right\|+L\left\|u_{n}\right\| .
\end{aligned}
$$

Using (2.13) in (2.11), we get

$$
\begin{aligned}
&\left\|x_{n+1}-p\right\| \\
& \leq\left\{\frac{1-\alpha_{n}}{1-(1-k) \alpha_{n}}+\frac{\alpha_{n}}{1-(1-k) \alpha_{n}}\left[L(L+1) \beta_{n}+L^{2}(L+1) \alpha_{n}\right]\right\} \\
& \times\left\|x_{n}-p\right\|+\frac{\alpha_{n}}{1-(1-k) \alpha_{n}} L(L+1)\left\|v_{n}\right\|+\frac{L}{1-(1-k) \alpha_{n}}\left\|u_{n}\right\| \\
& \leq {\left[1-\alpha_{n} \frac{k-L(L+1) \beta_{n}-L^{2}(L+1) \alpha_{n}}{1-(1-k) \alpha_{n}}\right]\left\|x_{n}-p\right\|+D \alpha_{n}\left\|v_{n}\right\|+D\left\|u_{n}\right\|, }
\end{aligned}
$$

where $D=\left(L^{2}+L\right) / k$. It follows from (2.3) and (2.14) that

$$
\left\|x_{n+1}-p\right\| \leq\left(1-r \alpha_{n}\right)\left\|x_{n}-p\right\|+D \alpha_{n}\left\|v_{n}\right\|+D\left\|u_{n}\right\|
$$

Put $a_{n}=\left\|x_{n}-p\right\|, w_{n}=r \alpha_{n}, b_{n}=(D / r)\left\|v_{n}\right\|$, and $c_{n}=D\left\|u_{n}\right\|$ for any $n \geq 0$. Then Lemma 1.1 ensures that $\left\|x_{n}-p\right\| \rightarrow 0$ as $n \rightarrow \infty$. This completes the proof.

THEOREM 2.2. Let $X, T,\left\{x_{n}\right\}_{n=0}^{\infty},\left\{\alpha_{n}\right\}_{n=0}^{\infty},\left\{\beta_{n}\right\}_{n=0}^{\infty}$, and $\left\{v_{n}\right\}_{n=0}^{\infty}$ be as in Theorem 2.1. Suppose that there exists a sequence $\left\{\gamma_{n}\right\}_{n=0}^{\infty}$ with $\lim _{n \rightarrow \infty} \gamma_{n}=0$ and $\left\|u_{n}\right\|=\gamma_{n} \alpha_{n}$ for any $n \geq 0$. Then $\left\{x_{n}\right\}_{n=0}^{\infty}$ converges strongly to the unique fixed point of $T$.

Proof. Just as in the proof of Theorem 2.1, we have

$$
\begin{aligned}
\left\|x_{n+1}-p\right\| & \leq\left(1-r \alpha_{n}\right)\left\|x_{n}-p\right\|+D \alpha_{n}\left\|v_{n}\right\|+D\left\|u_{n}\right\| \\
& =\left(1-r \alpha_{n}\right)\left\|x_{n}-p\right\|+D \alpha_{n}\left(\left\|v_{n}\right\|+\gamma_{n}\right) .
\end{aligned}
$$

Put $a_{n}=\left\|x_{n}-p\right\|, w_{n}=r \alpha_{n}, b_{n}=(D / r)\left(\left\|v_{n}\right\|+\gamma_{n}\right)$, and $c_{n}=0$ for any $n \geq 0$. Then Lemma 1.1 ensures that $\left\|x_{n}-p\right\| \rightarrow 0$ as $n \rightarrow \infty$. This completes the proof.

REMARK 2.3. Examples 2.4 and 2.5 show that Theorems 2.1 and 2.2 extend properly [3, Theorem 1], [1, Theorem 4.2], and [5, Theorem 1]. 
EXAMPLE 2.4. Let $X, T$ be as in Theorem 2.1 and

$$
\begin{gathered}
r=\frac{k}{2}, \quad \alpha_{n}=\frac{k}{4 L^{2}(L+1)(n+1)}, \quad \beta_{n}=\frac{k}{4 L(L+1)}, \\
\left\|u_{n}\right\|=\frac{1}{(n+1)^{2}}, \quad\left\|v_{n}\right\|=\frac{1}{n+1}
\end{gathered}
$$

for all $n \geq 0$. Then the conditions of Theorem 2.1 are satisfied. But [3, Theorem 1], [1, Theorem 4.2], and [5, Theorem 1] are not applicable.

EXAMPLE 2.5. Let $X, T, r,\left\{v_{n}\right\}_{n=0}^{\infty}$, and $\left\{\beta_{n}\right\}_{n=0}^{\infty}$ be as in Theorem 2.1. Put

$$
\alpha_{n}=\frac{k}{4 L^{2}(L+1) \sqrt{n+1}}, \quad\left\|u_{n}\right\|=\frac{1}{n+1}
$$

for all $n \geq 0$. Then the assumptions of Theorem 2.2 are fulfilled. However we do not invoke [3, Theorem 1], [1, Theorem 4.2], and [5, Theorem 1] to show the sequence $\left\{x_{n}\right\}_{n=0}^{\infty}$ converges strongly to the unique fixed point of $T$, because $\left\{\beta_{n}\right\}_{n=0}^{\infty}$ does not converge to 0 .

Now we prove the Ishikawa iterative procedure with errors is stable with respect to Lipschitz strong pseudocontraction.

THEOREM 2.6. Let $X, T,\left\{u_{n}\right\}_{n=0}^{\infty}$, and $\left\{v_{n}\right\}_{n=0}^{\infty}$ be as in Theorem 2.1. Define the sequence $\left\{x_{n}\right\}_{n=0}^{\infty}$ iteratively by $x_{0}, u_{0}, v_{0} \in X$,

$$
\begin{aligned}
z_{n} & =\left(1-\beta_{n}\right) x_{n}+\beta_{n} T x_{n}+v_{n}, \quad n \geq 0, \\
x_{n+1} & =\left(1-\alpha_{n}\right) x_{n}+\alpha_{n} T z_{n}+u_{n}, \quad n \geq 0,
\end{aligned}
$$

where $\left\{\alpha_{n}\right\}_{n=0}^{\infty}$ and $\left\{\beta_{n}\right\}_{n=0}^{\infty}$ are two real sequences satisfying (2.4) and

$$
\begin{gathered}
0<a \leq \alpha_{n} \leq 1, \quad 0 \leq \beta_{n} \leq 1, \quad n \geq 0 ; \\
\lim _{n \rightarrow \infty}\left\|v_{n}\right\|=\lim _{n \rightarrow \infty}\left\|u_{n}\right\|=0,
\end{gathered}
$$

where $a$ is a constant. Let $\left\{y_{n}\right\}_{n=0}^{\infty}$ be an arbitrary sequence in $X$. Define $\left\{\epsilon_{n}\right\}_{n=0}^{\infty} \subset$ $[0,+\infty)$ by

$$
\begin{aligned}
w_{n} & =\left(1-\beta_{n}\right) y_{n}+\beta_{n} T y_{n}+v_{n}, \quad n \geq 0, \\
\epsilon_{n} & =\left\|y_{n+1}-\left(1-\alpha_{n}\right) y_{n}-\alpha_{n} T w_{n}-u_{n}\right\|, \quad n \geq 0 .
\end{aligned}
$$

Then,

(1) the sequence $\left\{x_{n}\right\}_{n=0}^{\infty}$ converges strongly to the fixed point $p$ of $T$;

(2) $\left\|y_{n+1}-p\right\| \leq(1-a r)\left\|y_{n}-p\right\|+\epsilon_{n}+D\left\|v_{n}\right\|+D\left\|u_{n}\right\|, n \geq 0$, where $D=$ $\left(L^{2}+L\right) / k$

(3) $\lim _{n \rightarrow \infty} y_{n}=p \Leftrightarrow \lim _{n \rightarrow \infty} \epsilon_{n}=0$.

Proof. It follows from Theorem 2.1 that $x_{n} \rightarrow p$ as $n \rightarrow \infty$. This completes the proof of (1). 
Using (2.22), we have

$$
\left\|y_{n+1}-p\right\| \leq \epsilon_{n}+\left\|\left(1-\alpha_{n}\right) y_{n}+\alpha_{n} T w_{n}+u_{n}-p\right\|
$$

Set $P_{n}=\left(1-\alpha_{n}\right) y_{n}+\alpha_{n} T w_{n}+u_{n}$, then $\left(1-\alpha_{n}\right) y_{n}=P_{n}-\alpha_{n} T w_{n}-u_{n}$. As the proof in Theorem 2.1 and by (2.20), we obtain that

$$
\begin{aligned}
\left\|P_{n}-p\right\| & \leq\left(1-\alpha_{n} r\right)\left\|y_{n}-p\right\|+D \alpha_{n}\left\|v_{n}\right\|+D\left\|u_{n}\right\| \\
& \leq(1-\alpha r)\left\|y_{n}-p\right\|+D\left\|v_{n}\right\|+D\left\|u_{n}\right\| .
\end{aligned}
$$

Hence $\left\|y_{n+1}-p\right\| \leq(1-\alpha r)\left\|y_{n}-p\right\|+\epsilon_{n}+D\left\|v_{n}\right\|+D\left\|u_{n}\right\|$. This completes the proof of (2).

Now suppose that $\lim _{n \rightarrow \infty} y_{n}=p$. Then

$$
\begin{aligned}
\epsilon_{n} & =\left\|y_{n+1}-\left(1-\alpha_{n}\right) y_{n}-\alpha_{n} T w_{n}-u_{n}\right\| \\
& \leq\left\|y_{n+1}-p\right\|+\left\|\left(1-\alpha_{n}\right) y_{n}+\alpha_{n} T w_{n}+u_{n}-p\right\| \\
& \leq\left\|y_{n+1}-p\right\|+(1-\alpha r)\left\|y_{n}-p\right\|+D\left(\left\|v_{n}\right\|+\left\|u_{n}\right\|\right)
\end{aligned}
$$

It is easy to verify that $\epsilon_{n} \rightarrow 0$ as $n \rightarrow \infty$.

Next suppose that $\lim _{n \rightarrow \infty} \epsilon_{n}=0$. From (2.23) and (2.24), we obtain that

$$
\begin{aligned}
\left\|y_{n+1}-p\right\| & \leq\left(1-\alpha_{n} r\right)\left\|y_{n}-p\right\|+D \alpha_{n}\left\|v_{n}\right\|+D\left\|u_{n}\right\|+\epsilon_{n} \\
& \leq(1-\alpha r)\left\|y_{n}-p\right\|+D\left\|v_{n}\right\|+D\left\|u_{n}\right\|+\epsilon_{n}
\end{aligned}
$$

which means that $y_{n} \rightarrow p$ as $n \rightarrow \infty$ according to Lemma 1.1 and (2.21). This completes the proof of Theorem 2.6.

REMARK 2.7. Example 2.8 below shows that Theorem 2.6 extends substantially [11, Theorem 1] and [12, Theorem 3].

EXAMPLE 2.8. Let $X, T$ be as in Theorem 2.6 and

$$
\begin{array}{ccc}
r=\frac{k}{2}, & a=\frac{k}{16 L^{2}(L+1)}, & \alpha_{n}=\frac{k(n+1)}{8 L^{2}(L+1)(n+2)}, \\
\beta_{n}=\frac{k(n+1)}{4 L^{2}(L+1)(n+2)}, & \left\|u_{n}\right\|=\left\|v_{n}\right\|=\frac{1}{n+1}
\end{array}
$$

for $n \geq 0$. Then the conditions in Theorem 2.6 are fulfilled. But [11, Theorem 1] and [12, Theorem 3] are not applicable since $\alpha_{n}<\beta_{n}$ for all $n \geq 0$.

ACKNOWLEDGMENT. This work was supported by Korea Research Foundation Grant (KRF-2001-005-D00002). 


\section{REFERENCES}

[1] C. E. Chidume, Iterative approximation of fixed points of Lipschitzian strictly pseudocontractive mappings, Proc. Amer. Math. Soc. 99 (1987), no. 2, 283-288.

[2] __ An iterative process for nonlinear Lipschitzian strongly accretive mappings in $L_{p}$ spaces, J. Math. Anal. Appl. 151 (1990), no. 2, 453-461.

[3] C. E. Chidume and M. O. Osilike, Nonlinear accretive and pseudo-contractive operator equations in Banach spaces, Nonlinear Anal. 31 (1998), no. 7, 779-789.

[4] K. Deimling, Zeros of accretive operators, Manuscripta Math. 13 (1974), 365-374.

[5] L. Deng and X. P. Ding, Iterative approximation of Lipschitz strictly pseudocontractive mappings in uniformly smooth Banach spaces, Nonlinear Anal. 24 (1995), no. 7, 981-987.

[6] A. M. Harder and T. L. Hicks, Stability results for fixed point iteration procedures, Math. Japon. 33 (1988), no. 5, 693-706.

[7] T. Kato, Nonlinear semigroups and evolution equations, J. Math. Soc. Japan 19 (1967), 508-520.

[8] L. Liu, Approximation of fixed points of a strictly pseudocontractive mapping, Proc. Amer. Math. Soc. 125 (1997), no. 5, 1363-1366.

[9] L. S. Liu, Ishikawa and Mann iterative process with errors for nonlinear strongly accretive mappings in Banach spaces, J. Math. Anal. Appl. 194 (1995), no. 1, 114-125.

[10] M. O. Osilike, Stability results for the Ishikawa fixed point iteration procedure, Indian J. Pure Appl. Math. 26 (1995), no. 10, 937-945.

[11] Stable iteration procedures for strong pseudo-contractions and nonlinear operator equations of the accretive type, J. Math. Anal. Appl. 204 (1996), no. 3, 677-692.

[12] Stable iteration procedures for nonlinear pseudocontractive and accretive operators in arbitrary Banach spaces, Indian J. Pure Appl. Math. 28 (1997), no. 8, 10171029.

[13] K.-K. Tan and H. K. Xu, Iterative solutions to nonlinear equations of strongly accretive operators in Banach spaces, J. Math. Anal. Appl. 178 (1993), no. 1, 9-21.

Zeoing Liu: DePartment of MATHematics, Liaoning Normal University, P.O. Box 200, DALIAN, LIAONING 116029, CHINA

E-mail address: zeqingliu@sina.com.cn

Lili Zhang: DePartment of MATHematics, LiaOning Normal University, P.O. Box 200, DALIAN, LIAONING 116029, CHINA

Shin Min Kang: Department of Mathematics, Gyeongsang National University, CHINJU 660-701, KOREA

E-mail address: smkang@nongae.gsnu.ac.kr 


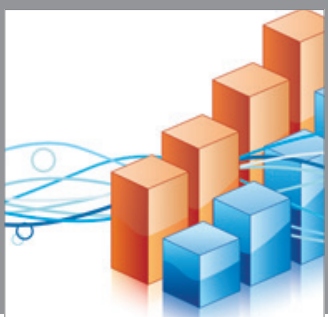

Advances in

Operations Research

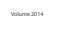

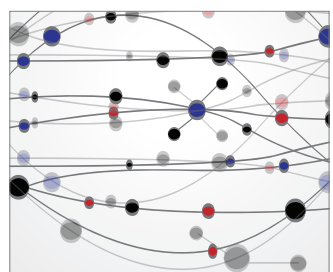

\section{The Scientific} World Journal
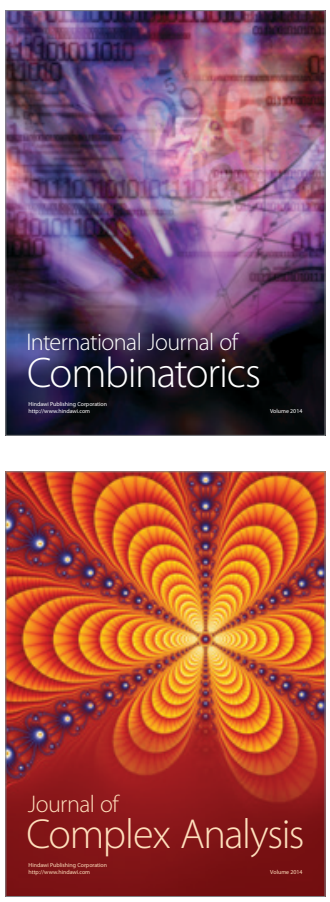

International Journal of

Mathematics and

Mathematical

Sciences
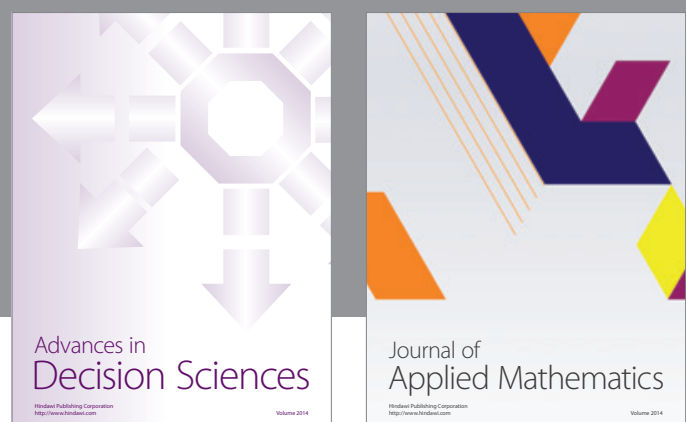

Journal of

Applied Mathematics
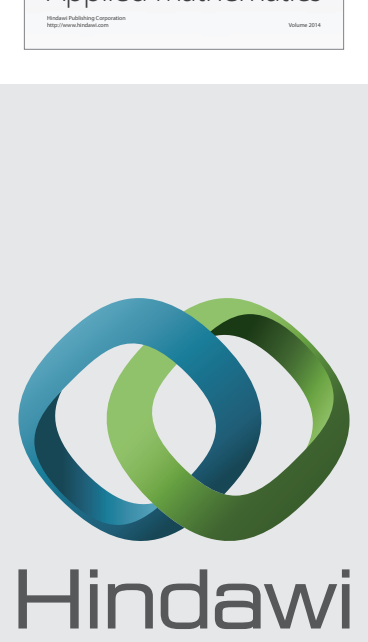

Submit your manuscripts at http://www.hindawi.com
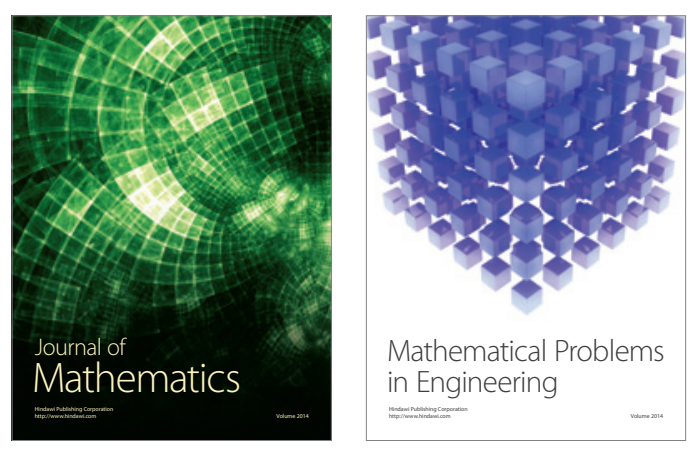

Mathematical Problems in Engineering
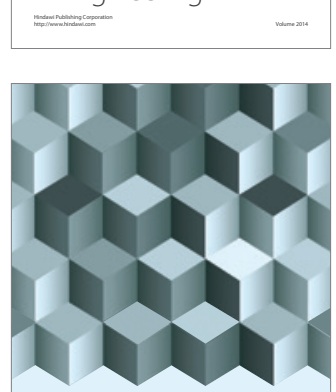

Journal of

Function Spaces
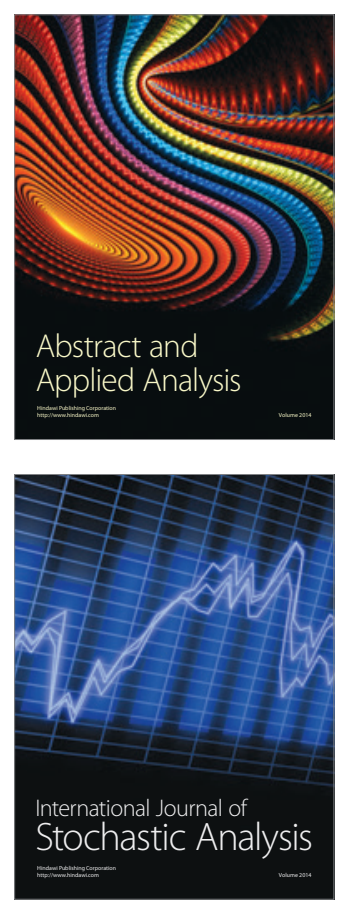

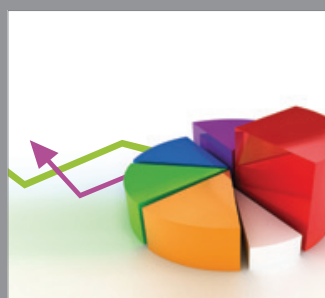

ournal of

Probability and Statistics

Promensencen
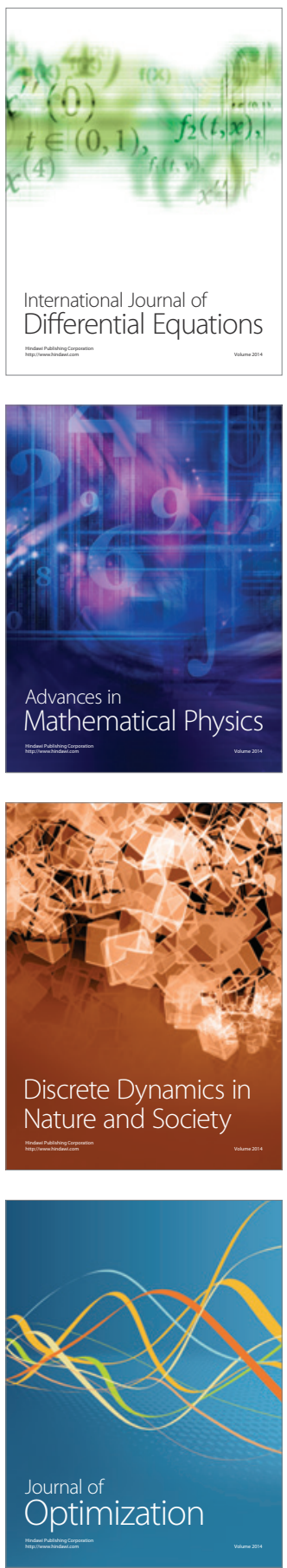